\title{
Effect of deposition atmosphere on the phase composition and microstructure of silicon carbide films prepared by laser chemical vapour deposition
}

\author{
Ryuma Hashimoto, Akihiko Ito ${ }^{*}$, Takashi Goto \\ Institute for Materials Research, Tohoku University, \\ 2-1-1 Katahira, Aoba-ku, Sendai 980-8577 Japan \\ "Corresponding author: E-mail: itonium@imr.tohoku.ac.jp \\ Tel: +81-22-215-2106; Fax: +81-22-215-2107
}

\begin{abstract}
SiC films were prepared by laser chemical vapour deposition using a Nd:YAG laser
in a $\mathrm{H}_{2}$ or $\mathrm{Ar}$ atmosphere. The effects of the deposition atmosphere on the film phase composition and microstructure were investigated. In a $\mathrm{H}_{2}$ atmosphere, (111)-oriented $\beta$-SiC films consisting of submicron-sized grains were grown at 1273-1473 K, while carbon was codeposited with the $\beta$-SiC films grown at $1573-1673 \mathrm{~K}$. In an Ar atmosphere, amorphous $\mathrm{Si}-\mathrm{C}-\mathrm{O}$ films were grown at $1073-1373 \mathrm{~K}$, while (111)-oriented $\beta$-SiC films that did not contain free carbon were grown at 1473-1723 K. The deposition rates of the (111)-oriented $\beta$-SiC films were $1500-2000 \mu \mathrm{m} \mathrm{h}^{-1}$.
\end{abstract}

Keywords: $\beta$-SiC; laser chemical vapour deposition; high-speed deposition; thick film 


\section{Introduction}

Silicon carbide $(\mathrm{SiC})$ shows promise as a protective material because of its excellent thermal shock and oxidisation resistances [1,2]. SiC coatings can be prepared by various techniques. For instance, chemical vapour deposition (CVD) is suitable for preparing high-purity, high-density, and conformal films at high deposition rates. Even though halide-based CVD is used extensively for the production of $\mathrm{SiC}$ films at relatively high deposition rates [3-5], this technique requires high deposition temperatures (greater than 1700 $\mathrm{K})$ and generates hazardous chlorides as by-products.

Films of various oxides [6,7], carbides [8], and nitrides [9] have been prepared at high deposition rates $\left(100-1000 \mu \mathrm{m} \mathrm{h}^{-1}\right)$ by laser CVD. $\beta$-SiC films have been grown on graphite substrates at a deposition rate of $2200 \mu \mathrm{m} \mathrm{h}^{-1}$ [8]. The high-speed epitaxial growth of (111)- and (110)-oriented $\beta$-SiC films has been achieved on (111) and (110) Si substrates, respectively [10].

Hexamethyldisilane (HMDS, $\mathrm{C}_{6} \mathrm{H}_{18} \mathrm{Si}_{2}$ ) has been used widely as a $\mathrm{SiC}$ precursor during CVD because its vapour pressure at room temperature is moderately high and because it does not form hazardous and corrosive by-products. However, its carbon content is three times that of silicon and results in free carbon being present in the synthesised SiC films. Free carbon degrades the chemical, mechanical, and electrical properties of $\mathrm{SiC}$ but can be removed by adding either $\mathrm{H}_{2}$ gas or an oxidant (i.e., $\mathrm{O}_{2}$ and $\mathrm{H}_{2} \mathrm{O}$ ), which form hydrocarbons (e.g., $\mathrm{CH}_{4}$ ) or carbonates (e.g., $\mathrm{CO}_{2}$ ) in gaseous form, respectively. For instance, the addition of $\mathrm{O}_{2}$ gas, which 
is a powerful oxidant of free carbon and may oxidise $\beta-\mathrm{SiC}$ to $\mathrm{SiO}_{2}$, is easy and safe. On the other hand, in the case of laser CVD, the source gases are activated by laser irradiation. Therefore, trace amounts of $\mathrm{O}_{2}$ in the common $\operatorname{Ar}$ gas $\left(\mathrm{O}_{2}\right.$ content less than $\left.2 \mathrm{ppm}\right)$ can eliminate the free carbon from the synthesised $\beta$-SiC films.

In the present study, $\mathrm{SiC}$ films were prepared by laser $\mathrm{CVD}$ in a $\mathrm{H}_{2}$ or $\mathrm{Ar}$ atmosphere, and the effects of the deposition atmosphere on the film phase composition and microstructure were investigated.

\section{Experimental}

The laser CVD apparatus used has been described in detail elsewhere [11]. HMDS

(LS-7120; Shin-Etsu Chemical, Japan) was evaporated at $293 \mathrm{~K}$ and its vapour was transported to the deposition chamber using $\mathrm{H}_{2}$ or $\mathrm{Ar}$ as the carrier gas. The $\mathrm{O}_{2}$ impurity level in the Ar gas was less than $2 \mathrm{ppm}$. The carrier gas was introduced into the chamber separately through a double-tube nozzle. The total pressure in the chamber was maintained at $800 \mathrm{~Pa}$. The entire graphite substrate $(10 \mathrm{~mm}$ in diameter and $1 \mathrm{~mm}$ in thickness) was irradiated with a continuous-wave Nd:YAG laser $(\lambda=1064 \mathrm{~nm})$. The deposition temperature $\left(T_{\mathrm{dep}}\right)$ was measured using a pyrometer. $T_{\text {dep }}$ was increased from 1073 to $1723 \mathrm{~K}$ by increasing the laser power from 60 to $245 \mathrm{~W}$. The deposition rate was calculated using the film thickness and deposition time (0.6 ks). 
The film phase compositions were determined through X-ray diffraction (XRD) analyses, which were performed using $\mathrm{Cu} \mathrm{K} \alpha$ radiation (Rigaku, Ultima-IV; $40 \mathrm{kV}$ and $40 \mathrm{~mA}$ ). The cross-sectional microstructures of the synthesised films were observed with a scanning electron microscopy (SEM) system (Hitachi, S-3100H) and a transmission electron microscopy (TEM) system (Topcon, EM-002B). The binding energies of the $\mathrm{C}, \mathrm{Si}$, and $\mathrm{O}$ atoms were measured with X-ray photoelectron spectroscopy (XPS), which was performed using $\mathrm{Al} \mathrm{K \alpha}$ radiation (Shimadzu-Kratos AXIS-ULTRA DLD). The spectra were fitted with a Gaussian function with baseline correction. The $\mathrm{C}-\mathrm{C}$ peak at $284.8 \mathrm{eV}$ was used as the charge reference.

\section{Results and discussion}

\section{1 $\mathrm{SiC}$ films prepared in a $\mathrm{H}_{2}$ atmosphere}

Figure 1 shows the XRD patterns of $\mathrm{SiC}$ films prepared at various $T_{\text {dep }}$ in a $\mathrm{H}_{2}$ atmosphere. Only peaks related to the graphite substrate were observed at $1173 \mathrm{~K}$, implying that the corresponding film was amorphous (Fig. 1(a)). In the case of the film grown at $1273 \mathrm{~K}$, a broad peak was observed at $2 \theta=36^{\circ}$; this was indexed as belonging to $111 \beta$-SiC (ICSD \#24217) (Fig. 1(b)). A (111)-oriented $\beta$-SiC film was obtained at $1473 \mathrm{~K}$ (Fig. 1(c)). At $1673 \mathrm{~K}$, carbon was codeposited with the synthesised (111)-oriented $\beta$-SiC film (Fig. 1(d)). The (0001) peak at $2 \theta=$ $26^{\circ}$ could be deconvoluted into two peaks, which were attributable to the deposited carbon $(2 \theta=$ $\left.25.5^{\circ}\right)$ and the graphite substrate $\left(2 \theta=26.4^{\circ}\right)$. 
Figure 2 shows the $\mathrm{Si} 2 p$ XPS spectra of $\mathrm{SiC}$ films prepared at various $T_{\text {dep }}$ in a $\mathrm{H}_{2}$ atmosphere. In the case of the film grown at $1173 \mathrm{~K}$, the Si $2 p$ peak could be deconvoluted into peaks related to $\mathrm{Si}-\mathrm{C}_{4}, \mathrm{Si}-\mathrm{C}_{3}-\mathrm{O}, \mathrm{Si}-\mathrm{C}_{2}-\mathrm{O}_{2}$, and $\mathrm{Si}-\mathrm{C}-\mathrm{O}_{3}$ (Fig. 2(a)). The $\mathrm{Si} 2 p$ binding energies in $\mathrm{SiC}\left(\mathrm{Si}-\mathrm{C}_{4}\right)$ and $\mathrm{SiO}_{2}\left(\mathrm{Si}-\mathrm{O}_{4}\right)$ are $100-101$ and $103-104 \mathrm{eV}$, respectively. The $\mathrm{Si} 2 p$ peak observed at approximately $101 \mathrm{eV}$ was associated with $\mathrm{Si}-\mathrm{C}_{4}(101.0 \mathrm{eV}), \mathrm{Si}-\mathrm{C}_{3}-\mathrm{O}(101.8 \mathrm{eV})$, $\mathrm{Si}-\mathrm{C}_{2}-\mathrm{O}_{2}(102.4 \mathrm{eV}), \mathrm{Si}-\mathrm{C}-\mathrm{O}_{3}(102.9 \mathrm{eV})$, and $\mathrm{Si}-\mathrm{O}_{4}(103.6 \mathrm{eV})$ [12-15]. The $\mathrm{C}$ atoms in the $\mathrm{Si}-\mathrm{C}_{4}$ tetrahedron were partially substituted by an $\mathrm{O}$ atom. Therefore, the amorphous nature of the film prepared at $1173 \mathrm{~K}$ may explain the formation of the $\mathrm{Si}-\mathrm{C}-\mathrm{O}$ film. The presence of residual oxygen in the precursor furnace and the deposition chamber may account for the formation of $\mathrm{Si}-\mathrm{C}-\mathrm{O}$. At $1473 \mathrm{~K}$, the $\mathrm{Si} 2 p$ peak became slightly sharper and almost fitted the spectrum of $\mathrm{Si}_{-} \mathrm{C}_{4}$ at $101.0 \mathrm{eV}$ (Fig. 2(b)).

Figure 3 shows cross-sectional SEM and TEM images of the SiC films prepared at 1473 and $1673 \mathrm{~K}$ in a $\mathrm{H}_{2}$ atmosphere. At $1473 \mathrm{~K}$, the deposited $\mathrm{SiC}$ film consisted of fine grains (Fig. 3(a)). Further, the nanosized $\beta$-SiC particles formed a three-dimensional network (Fig. 3(b)). We estimated their grain size to be $98 \mathrm{~nm}$ using the Debye-Scherrer equation; this value was in agreement with the TEM observations. The selected-area electron diffraction (SAED) pattern showed a Debye-Scherrer ring, which was indexed as belonging to $\beta$-SiC (inset, Fig. $3(b))$.

The $\beta$-SiC film prepared at $1673 \mathrm{~K}$ displayed a lamellar structure in the cross-sectional 
SEM and TEM images (Figs. 3(c) and 3(d)). The arc-like patterns and diffraction spots observed in its SAED pattern were attributable to carbon and $\beta$-SiC, respectively (inset, Fig. 3(d)). Consequently, the lamellar structure corresponded to (0001)-oriented carbon, whereas the vertical grains (darker part) were associated with (111)-oriented $\beta$-SiC.

\subsection{SiC films prepared in an Ar atmosphere}

Figure 4 shows the XRD patterns of SiC films prepared at various $T_{\text {dep }}$ in an Ar atmosphere. At $1173 \mathrm{~K}$, only peaks related to the graphite substrate were observed, indicating that the corresponding film was amorphous (Fig. 4(a)). At $1273 \mathrm{~K}$, a halo pattern was observed at $2 \theta=$ $36^{\circ}$ (Fig. 4(b)). The XRD patterns of the films formed at 1473 (Fig. 4(c)) and $1673 \mathrm{~K}$ (Fig. 4(d)) suggested that the films had a (111) orientation. The (111) orientation became more pronounced at $1673 \mathrm{~K}$; however, no free carbon was detected in the $\beta$-SiC films prepared at temperatures of $1473-1673 \mathrm{~K}$.

Figure 5 shows the $\mathrm{Si} 2 p$ XPS spectra of $\mathrm{SiC}$ films prepared at various $T_{\mathrm{dep}}$ in an $\mathrm{Ar}$ atmosphere. In the case of the film synthesised at $1073 \mathrm{~K}$, the Si $2 p$ peak could be deconvoluted into those corresponding to $\mathrm{Si}-\mathrm{C}_{4}, \mathrm{Si}-\mathrm{C}_{3}-\mathrm{O}, \mathrm{Si}-\mathrm{C}_{2}-\mathrm{O}_{2}, \mathrm{Si}-\mathrm{C}-\mathrm{O}_{3}$, and $\mathrm{Si}-\mathrm{O}_{4}$ (Fig. 5(a)). When $T_{\text {dep }}$ was increased from 1073 to $1473 \mathrm{~K}$, the $\mathrm{Si} 2 p$ peak observed was almost similar to that for $\mathrm{Si}-\mathrm{C}_{4}$ (Fig. 5(c)).

Figure 6 shows cross-sectional SEM and TEM images of the SiC films prepared at 
1273 and $1723 \mathrm{~K}$ in an $\mathrm{Ar}$ atmosphere. The $\mathrm{Si}-\mathrm{C}-\mathrm{O}$ film prepared at $1273 \mathrm{~K}$ had an amorphous structure (Fig. 6(a); no grains were observed in the TEM images (Fig. 6(b)). The SAED pattern of the film showed a Debye ring that could be indexed as belonging to $\beta$-SiC (inset, Fig. 6(b)). On the other hand, the $\beta-\mathrm{SiC}$ film prepared at $1723 \mathrm{~K}$ consisted of columnar grains with conical tops (Figs. 6(c) and 6(d)). Its SAED pattern confirmed that the columnar grains grew in the (111) direction (inset, Fig. 6(d)).

3.3 Comparison of phases and microstructures of films synthesised in $\mathrm{H}_{2}$ and Ar atmospheres

Figure 7 displays the phases and microstructures of the films synthesised in $\mathrm{H}_{2}$ and $\mathrm{Ar}$ atmospheres. In the $\mathrm{H}_{2}$ atmosphere, when $T_{\text {dep }}$ was increased from 1073 to $1523 \mathrm{~K}$, the $\mathrm{Si}-\mathrm{C}-\mathrm{O}$ phase transformed into $\beta$-SiC, with a mixture of $\beta$-SiC and carbon resulting eventually. The $\mathrm{Si}-\mathrm{C}-\mathrm{O}$ films formed at $1173-1473 \mathrm{~K}$ were amorphous, whereas the $\beta$-SiC films consisted of nanosized grains assembled into a three-dimensional network. The $\beta$-SiC/carbon mixture exhibited a lamellar structure at $1673 \mathrm{~K}$. Therefore, it can be assumed that, in the $\mathrm{H}_{2}$ atmosphere, the small amount of $\mathrm{O}$ present contaminated the $\beta-\mathrm{SiC}$ film at a low $T_{\text {dep }}(\sim 1273 \mathrm{~K})$. Further, the free-carbon content increased with an increase in $T_{\mathrm{dep}}$.

In the $\mathrm{Ar}$ atmosphere, amorphous $\mathrm{Si}-\mathrm{C}-\mathrm{O}$ films were formed for temperatures of 1073-1373 K, whereas (111)-oriented $\beta$-SiC films were formed at temperatures greater than 
$1423 \mathrm{~K}$. When $T_{\text {dep }}$ was increased from 1423 to $1723 \mathrm{~K}$, the (111) orientation of the $\beta$-SiC films became more pronounced, and their microstructure changed from cauliflower-like to columnar. No carbon was identified in the $\beta$-SiC films. Highly crystalline (111)-oriented $\beta$-SiC films were grown at $1423 \mathrm{~K}$ using the Nd:YAG laser. This $T_{\text {dep }}$ value is lower than that for similar films obtained by conventional thermal CVD and laser CVD using a $\mathrm{CO}_{2}$ laser [8]. The $\mathrm{CO}_{2}$ laser has a longer wavelength $(10.6 \mu \mathrm{m})$, which falls in the infrared region, and might not interact with the gas phase. In contrast, the Nd:YAG laser has a medium wavelength $(1064 \mathrm{~nm})$ and can interact with the precursor gases. As a result, intermediate species can form [16]. Presumably, this is why the Nd:YAG laser produced $\beta$-SiC films at a lower $T_{\text {dep }}$ value than that for the $\mathrm{CO}_{2}$ laser.

Figure 8 shows the relation between the reciprocal of $T_{\text {dep }}$ and the deposition rate $\left(R_{\text {dep }}\right)$ of SiC films formed by conventional CVD and laser CVD. Table 1 lists the experimental conditions. In this study, in the $\mathrm{H}_{2}$ atmosphere, when $T_{\text {dep }}$ was increased from 1173 to $1473 \mathrm{~K}$, $R_{\text {dep }}$ increased from 10 to $1400 \mu \mathrm{m} \mathrm{h}^{-1}$ before decreasing to $200 \mu \mathrm{m} \mathrm{h}^{-1}$ at temperatures greater than $1473 \mathrm{~K}$. In the Ar atmosphere, $R_{\text {dep }}$ increased from 10 to $2000 \mu \mathrm{m} \mathrm{h}^{-1}$ when $T_{\text {dep }}$ was increased from 1073 to $1473 \mathrm{~K}$ before decreasing to $600 \mu \mathrm{m} \mathrm{h}^{-1}$ at temperatures greater than $1473 \mathrm{~K} . R_{\text {dep }}$ increased exponentially with an increase in $T_{\text {dep }}$ at temperatures below $1500 \mathrm{~K}$ in both the $\mathrm{H}_{2}$ and the Ar atmosphere, leading to activation energies $\left(E_{\mathrm{a}}\right)$ of 150 and $238 \mathrm{~kJ} \mathrm{~mol}^{-1}$, respectively. In the case of CVD, activation energies $\left(E_{\mathrm{a}}\right)$ greater than $100 \mathrm{~kJ} \mathrm{~mol}^{-1}$ generally 
correspond to reaction-limited processes on the substrate surface, whereas low $E_{\mathrm{a}}$ values (i.e., those on the order of several tens of $\mathrm{kJ} \mathrm{mol}^{-1}$ ) are indicative of diffusion-limited processes in the gas phase [17]. Therefore, it can be concluded that, in this study, the $\beta$-SiC films were deposited through a reaction-limited process at temperatures below $1500 \mathrm{~K}$. The decrease in $R_{\text {dep }}$ at temperatures greater than $1500 \mathrm{~K}$ may result from premature gas-phase reactions, such as those related to powder formation.

Halide CVD using $\mathrm{SiCl}_{4}$ and hydrocarbon precursors produces $\beta$-SiC films at high $R_{\text {dep }}$ but requires high $T_{\text {dep }}$ values $(1700-1900 \mathrm{~K})$ to achieve highly crystalline films $[4,5]$. Plasma-enhanced, low-pressure, and atmospheric-pressure CVD processes can produce $\beta$-SiC films at temperatures lower than $1300 \mathrm{~K}$ at $R_{\text {dep }}$ of $0.01-10 \mu \mathrm{m} \mathrm{h}^{-1}$ [18-24], values that are 100 times lower than those observed in the present study. Metalorganic compounds, such as tetramethylsilane (TMS: $\left.\quad \mathrm{Si}\left(\mathrm{CH}_{3}\right)_{4}\right) \quad$ [25], monomethylsilane $\quad\left(\mathrm{MMS}: \quad \mathrm{CH}_{3} \mathrm{SiH}_{3}\right.$ ) [22], 1,3-disilacyclobutane (DSB: $\mathrm{SiH}_{3} \mathrm{CH}_{2}-\mathrm{SiH}_{2} \mathrm{CH}_{3}$ ) [24], and hexamethyldisilane (HMDS: $\left.\mathrm{Si}\left(\mathrm{CH}_{3}\right)_{3}-\mathrm{Si}\left(\mathrm{CH}_{3}\right)_{3}\right)[8,10,15,20,23]$, are typically used as precursors during metalorganic CVD. In addition, $\mathrm{H}_{2}$ gas is used at high flow rates to generate $\beta$-SiC films that do not contain any free carbon; however, this significantly degrades the deposition rate. In this study, $\beta$-SiC films without free carbon could be deposited in an Ar atmosphere between 1473 and $1673 \mathrm{~K}$ at significantly high deposition rates $\left(1500-2000 \mu \mathrm{m} \mathrm{h}^{-1}\right)$. 


\section{Conclusions}

$\beta$-SiC films were deposited by laser CVD using a Nd:YAG laser. In a $\mathrm{H}_{2}$ atmosphere, the amorphous $\mathrm{Si}-\mathrm{C}-\mathrm{O}$ phase transformed into $\beta-\mathrm{SiC}$, eventually resulting in a mixture of $\beta$-SiC and carbon, as the deposition temperature was increased. The $\beta$-SiC films comprised fine submicron-sized grains, which formed a three-dimensional network. The $\beta$-SiC phase with small amounts of free carbon had a lamellar structure. In an Ar atmosphere, the amorphous $\mathrm{Si}-\mathrm{C}-\mathrm{O}$ phase produced $\beta-\mathrm{SiC}$ with an increase in $T_{\text {dep }}$. $\beta$-SiC films without free carbon were obtained at temperatures of $1473-1673 \mathrm{~K}$ at $R_{\text {dep }}$ values of $1500-2000 \mu \mathrm{m} \mathrm{h}^{-1}$. These films exhibited a (111)-oriented columnar structure.

\section{Acknowledgments}

This research was supported in part by a Grant-in-Aid for Young Scientists (A) (No. 25709069) from the Japan Society for the Promotion of Science (JSPS) and a Grant-in-Aid for Challenging Exploratory Research (No. 25630273) from JSPS. This work was also supported by Council for Science, Technology and Innovation (CSTI), Cross-ministerial Strategic Innovation Promotion Program (SIP) (Funding agency: JST). 


\section{References}

[1] M.E. Westwood, J.D. Webster, R.J. Day, F.H. Hayes, R. Taylor, Oxidation protection for carbon fibre composites, J. Mater. Sci. 31 (1996) 1389-1397.

[2] D. McDanels, Analysis of stress-strain, fracture, and ductility behavior of aluminum matrix composites containing discontinuous silicon carbide reinforcement, Metall. Mater. Trans. A. 16 (1985) 1105-1115.

[3] J. Schlichting, Chemical vapor deposition of silicon carbide, Powder Metall. Int. 12 (1980) 141-147.

[4] T. Hirai, T. Goto, T. Kaji, Preparation of silicon carbide by chemical vapor deposition, J. Ceram. Assoc. Jpn. 91 (1983) 502-509.

[5] M.X. Han, W. Zhou, D.H. Zheng, R. Tu, S. Zhang, T. Goto, High-speed deposition of sic thick film by halide precursor, Key Eng. Mater. 616 (2014) 37-42.

[6] Y. You, A. Ito, T. Goto, Highly (001)-oriented $\alpha-\mathrm{Al}_{2} \mathrm{O}_{3}$ films prepared by laser chemical vapor deposition, Mater. Lett. 106 (2013) 11-13.

[7] D. Guo, A. Ito, R. Tu, T. Goto, Microstructure and dielectric response of (111)-oriented tetragonal $\mathrm{BaTiO}_{3}$ thick films prepared by laser chemical vapor deposition, J. Asian Ceram. Soc. 1 (2013) 197-201.

[8] K. Fujie, A. Ito, R. Tu, T. Goto, Laser chemical vapor deposition of SiC films with $\mathrm{CO}_{2}$ laser, J. Alloys Compd. 502 (2010) 238-242. 
Ti(C,N)-based cermet substrate using $\operatorname{Ti}(\mathrm{O} i \operatorname{Pr})_{2}(\mathrm{dpm})_{2}-\mathrm{NH}_{3}$ system, J. Ceram. Soc. Jpn. 119 (2011) 310-313.

[10] S. Zhang, Q. Xu, R. Tu, T. Goto, L. Zhang, High-speed preparation of $\langle 111\rangle-$ and $<110>$-oriented $\beta$-sic films by laser chemical vapor deposition, J. Am. Ceram. Soc. 97 (2014) 952-958.

[11] A. Ito, H. Kadokura, T. Kimura, T. Goto, Texture and orientation characteristics of $\alpha-\mathrm{Al}_{2} \mathrm{O}_{3}$ films prepared by laser chemical vapor deposition using Nd:YAG laser, J. Alloys Compd. 489 (2010) 469-474.

[12] G.D. Sorarù, G. D'Andrea, A. Glisenti, XPS characterization of gel-derived silicon oxycarbide glasses, Mater. Lett. 27 (1996) 1-5.

[13] C. $\mathrm{O} \square$ nneby, Silicon oxycarbide formation on $\mathrm{SiC}$ surfaces and at the $\mathrm{SiC} / \mathrm{SiO}_{2}$ interface, J. Vac. Sci. Technol. Vac. Surf. Films. 15 (1997) 1597.

[14] R.P. Socha, K. Laajalehto, P. Nowak, Oxidation of the silicon carbide surface in Watts' plating bath, Surf. Interface Anal. 34 (2002) 413-417.

[15] S. Yu, A. Ito, R. Tu, T. Goto, Dome-like and dense $\mathrm{SiC}_{-} \mathrm{SiO}_{2}$ nanocomposite films synthesized by laser chemical vapor deposition using $\mathrm{CO}_{2}$ laser, Surf. Coat. Technol. 205 (2011) 2818-2822.

[16] M. Gao, A. Ito, T. Goto, Effect of laser wavelength on phase and microstructure of $\mathrm{TiO}_{2}$ 
films prepared by laser chemical vapor deposition, Surf. Coat. Technol. 244 (2014) $166-172$.

[17] W.A. Bryant, The fundamentals of chemical vapour deposition, J. Mater. Sci. 12 (1977) $1285-1306$.

[18] J.-Y. Seo, S.-Y. Yoon, K. Niihara, K.H. Kim, Growth and microhardness of SiC films by plasma-enhanced chemical vapor deposition, Thin Solid Films. 406 (2002) 138-144.

[19] H.-T. Chiu, J.-S. Hsu, Low pressure chemical vapor deposition of silicon carbide thin films from hexamethyldisilane, Thin Solid Films. 252 (1994) 13-18.

[20] K. Takahashi, S. Nishino, J. Saraie, Low-temperature growth of 3c-sic on Si substrate by chemical vapor deposition using hexamethyldisilane as a source material, J. Electrochem. Soc. 139 (1992) 3565-3571.

[21] J. Rodríguez-Viejo, J. Stoemenos, N. Clavaguera, M.T. Clavaguera-Mora, Growth morphology of low-pressure metalorganic chemical vapor deposition silicon carbide on a-SiO $2 / \mathrm{Si}(100)$ substrates, J. Cryst. Growth. 155 (1995) 214-222.

[22] Y. Ohshita, Reactants in $\mathrm{SiC}$ chemical vapor deposition using $\mathrm{CH}_{3} \mathrm{SiH}_{3}$ as a source gas, $\mathrm{J}$. Cryst. Growth. 147 (1995) 111-116.

[23] C.H. Wu, C. Jacob, X.J. Ning, S. Nishino, P. Pirouz, Epitaxial growth of 3C-SiC on Si(111) from hexamethyldisilane, J. Cryst. Growth. 158 (1996) 480-490.

[24] M.B.J. Wijesundara, G. Valente, W.R. Ashurst, R.T. Howe, A.P. Pisano, C. Carraro, R. 
Maboudian, Single-source chemical vapor deposition of 3c-sic films in a LPCVD reactor i.

growth, structure, and chemical characterization, J. Electrochem. Soc. 151 (2004)

C210-C214.

[25] S. Veintemillas-Verdaguer, A. Figueras, R. Rodriguez-Clemente, A thermodynamical approach to tetramethylsilane (TMS) pyrolysis; application to SiC coatings obtained by MOCVD, J. Cryst. Growth. 128 (1993) 349-353. 


\section{Figure captions}

Figure 1

XRD patterns of the $\mathrm{SiC}$ films prepared in a $\mathrm{H}_{2}$ atmosphere at $T_{\text {dep }}$ of (a)

$1173 \mathrm{~K}$, (b) $1273 \mathrm{~K}$, (c) $1473 \mathrm{~K}$, and (d) $1673 \mathrm{~K}$.

Figure 2

Si $2 p$ XPS spectra of the SiC films prepared in a $\mathrm{H}_{2}$ atmosphere at $T_{\text {dep }}$ of (a)

$1173 \mathrm{~K}$ and (b) $1473 \mathrm{~K}$.

Figure 3

(a, c) Cross-sectional SEM and (b, d) TEM images of the SiC films prepared in a $\mathrm{H}_{2}$ atmosphere at $T_{\text {dep }}$ of $(\mathrm{a}, \mathrm{b}) 1473 \mathrm{~K}$ and $(\mathrm{c}, \mathrm{d}) 1673 \mathrm{~K}$. Insets show the corresponding SAED patterns.

Figure 4 XRD patterns of the SiC films prepared in an Ar atmosphere at $T_{\text {dep }}$ of (a) $1173 \mathrm{~K}$, (b) $1273 \mathrm{~K}$, (c) $1473 \mathrm{~K}$, and (d) $1673 \mathrm{~K}$.

Figure 5 Si $2 p$ XPS spectra of the SiC films prepared in an Ar atmosphere at $T_{\text {dep }}$ of (a) $1073 \mathrm{~K}$, (b) $1273 \mathrm{~K}$, and (c) $1473 \mathrm{~K}$.

Figure 6 (a, c) Cross-sectional SEM and (b, d) TEM images of the SiC films prepared in an $\mathrm{Ar}$ atmosphere at $T_{\text {dep }}$ of (a, b) $1273 \mathrm{~K}$ and (c, d) $1723 \mathrm{~K}$. Insets show 
the corresponding SAED patterns.

Figure 7

Phases and microstructures of the SiC films prepared in (a) $\mathrm{H}_{2}$ and (b) $\mathrm{Ar}$ atmospheres.

Figure 8

Relationship between the reciprocal of $T_{\text {dep }}$ and $R_{\text {dep }}$ for $\mathrm{SiC}$ films grown using conventional CVD and laser CVD. 


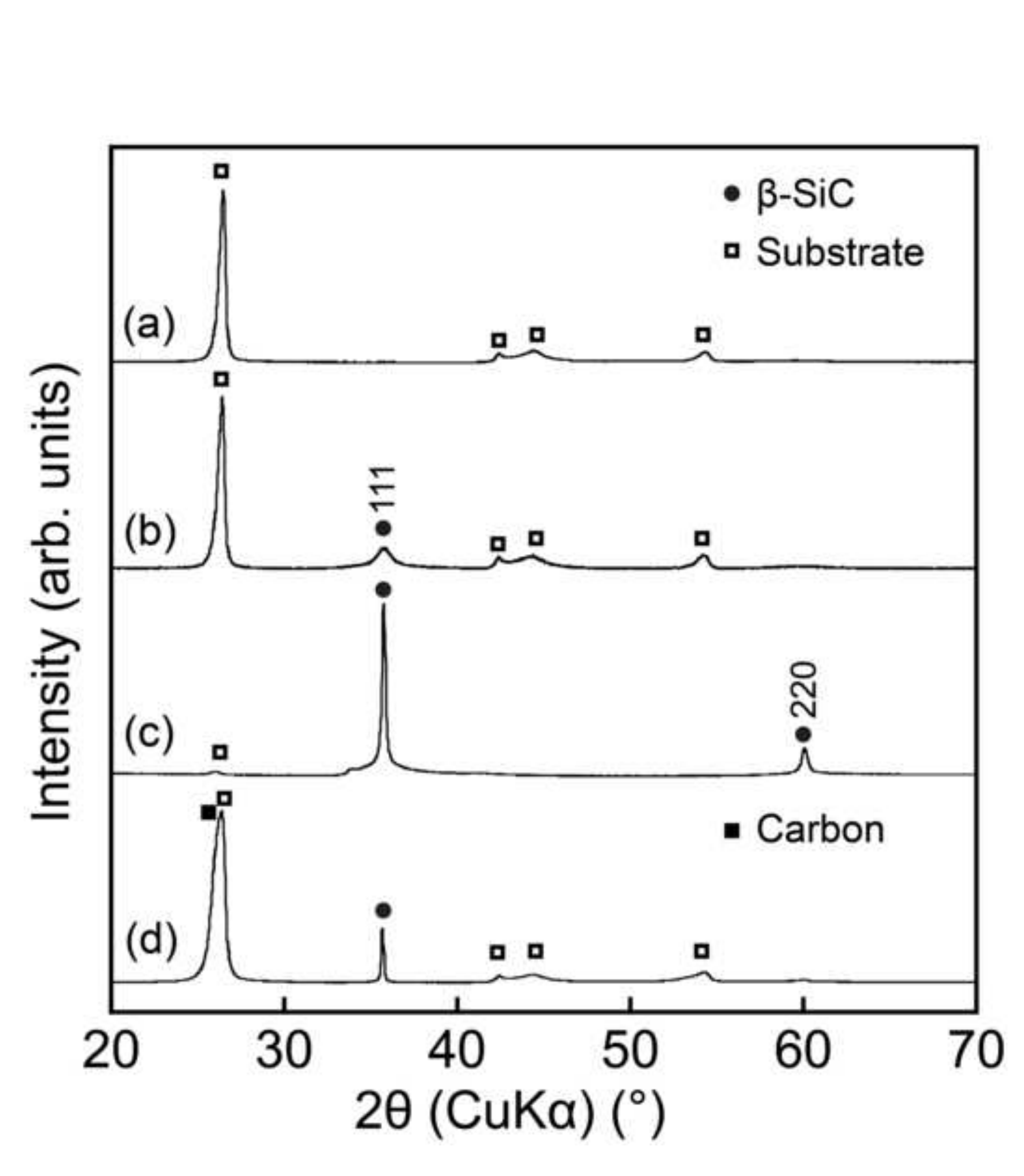

Fig.01
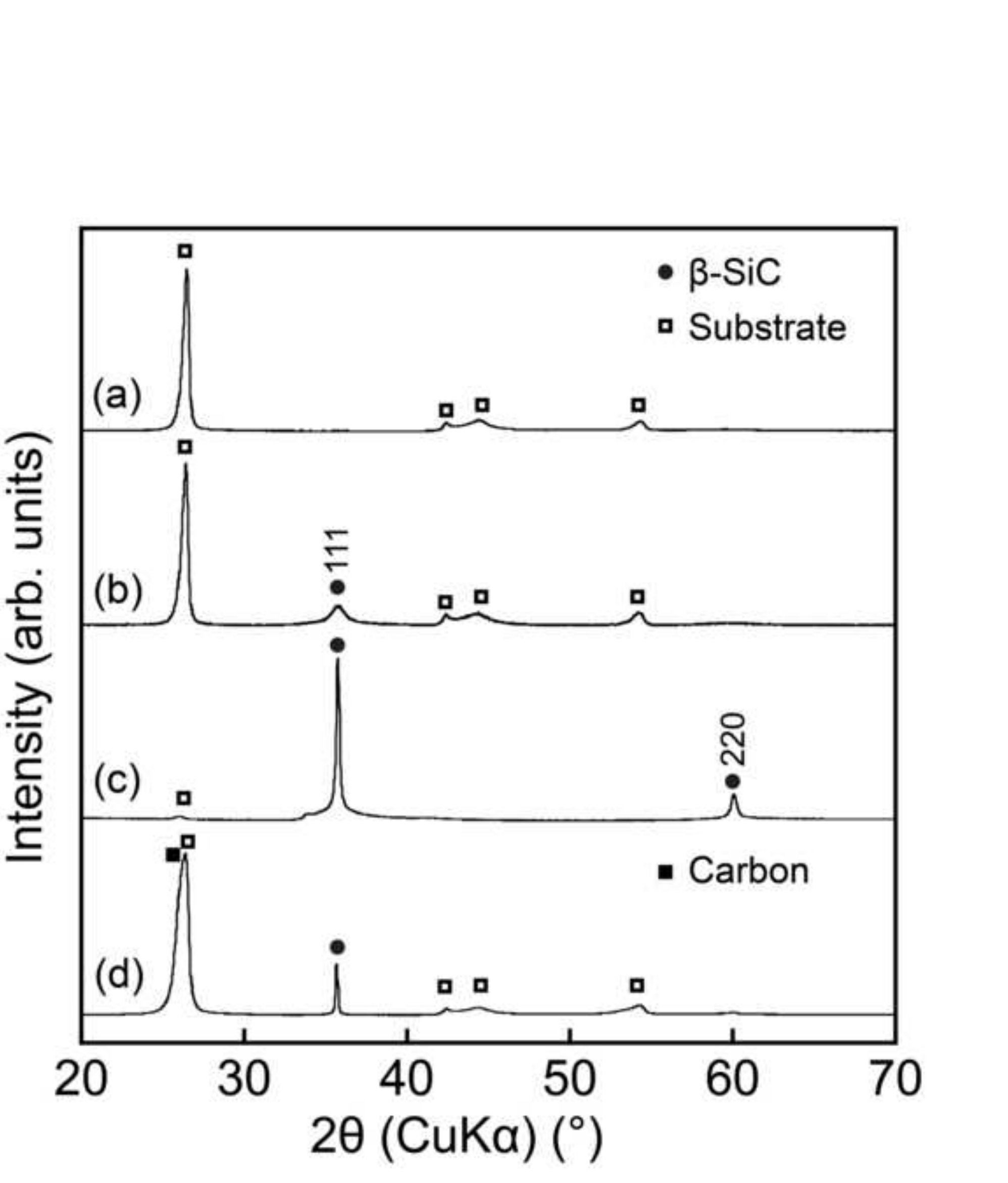

(

\section{te}




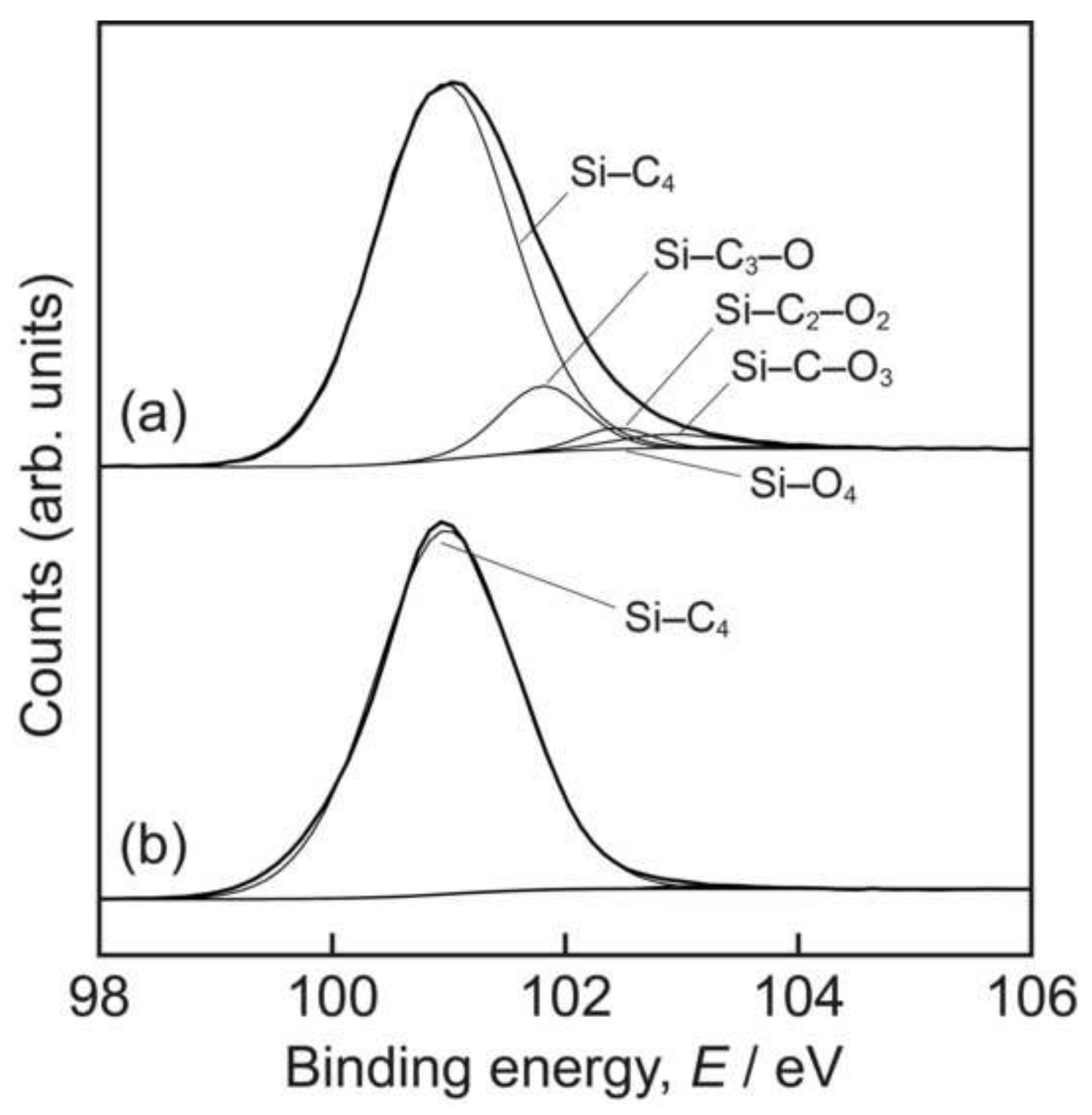

Fig.02 
(a)

$50 \mu \mathrm{m}$ (b)

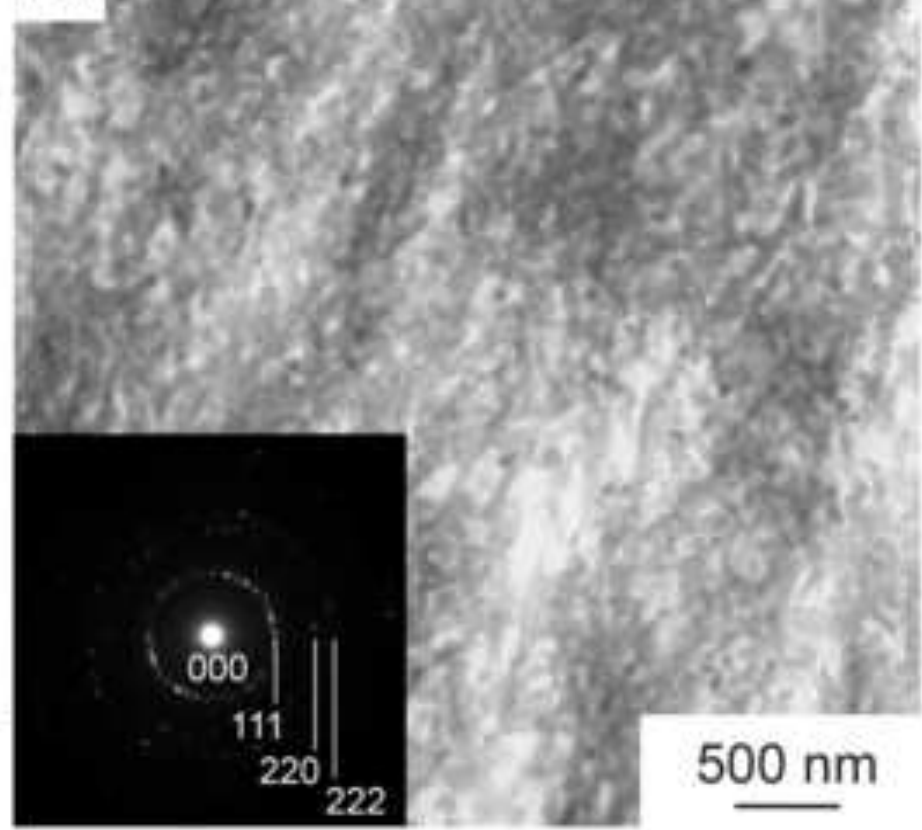

(d)

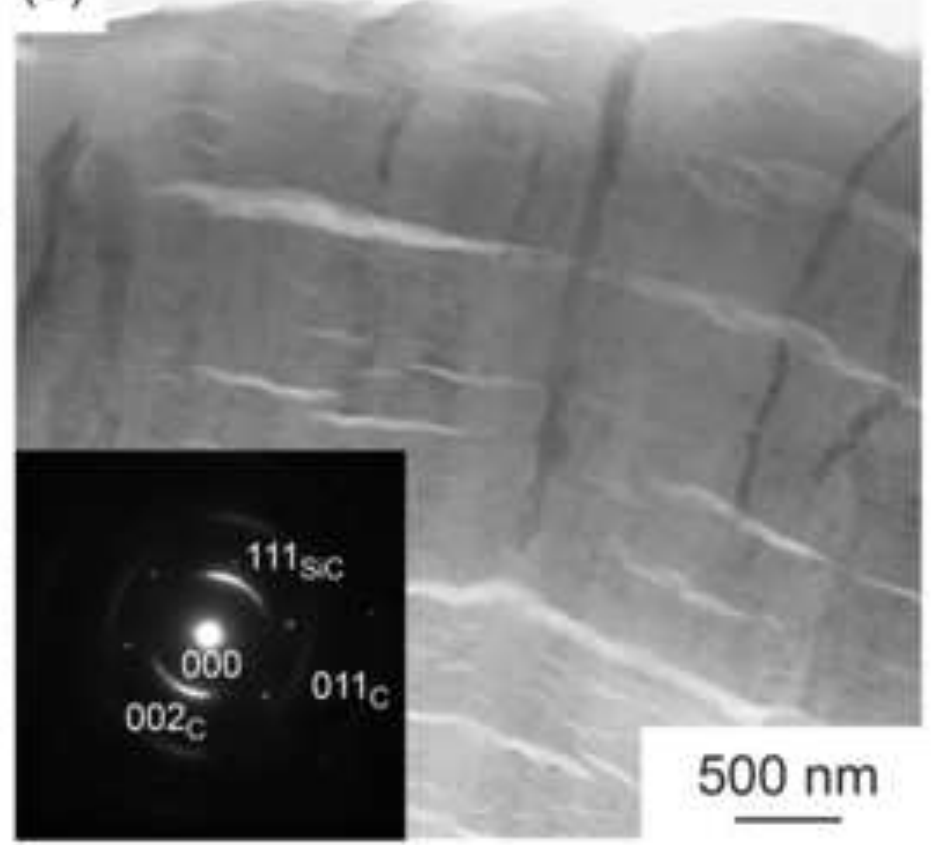


Fig.05

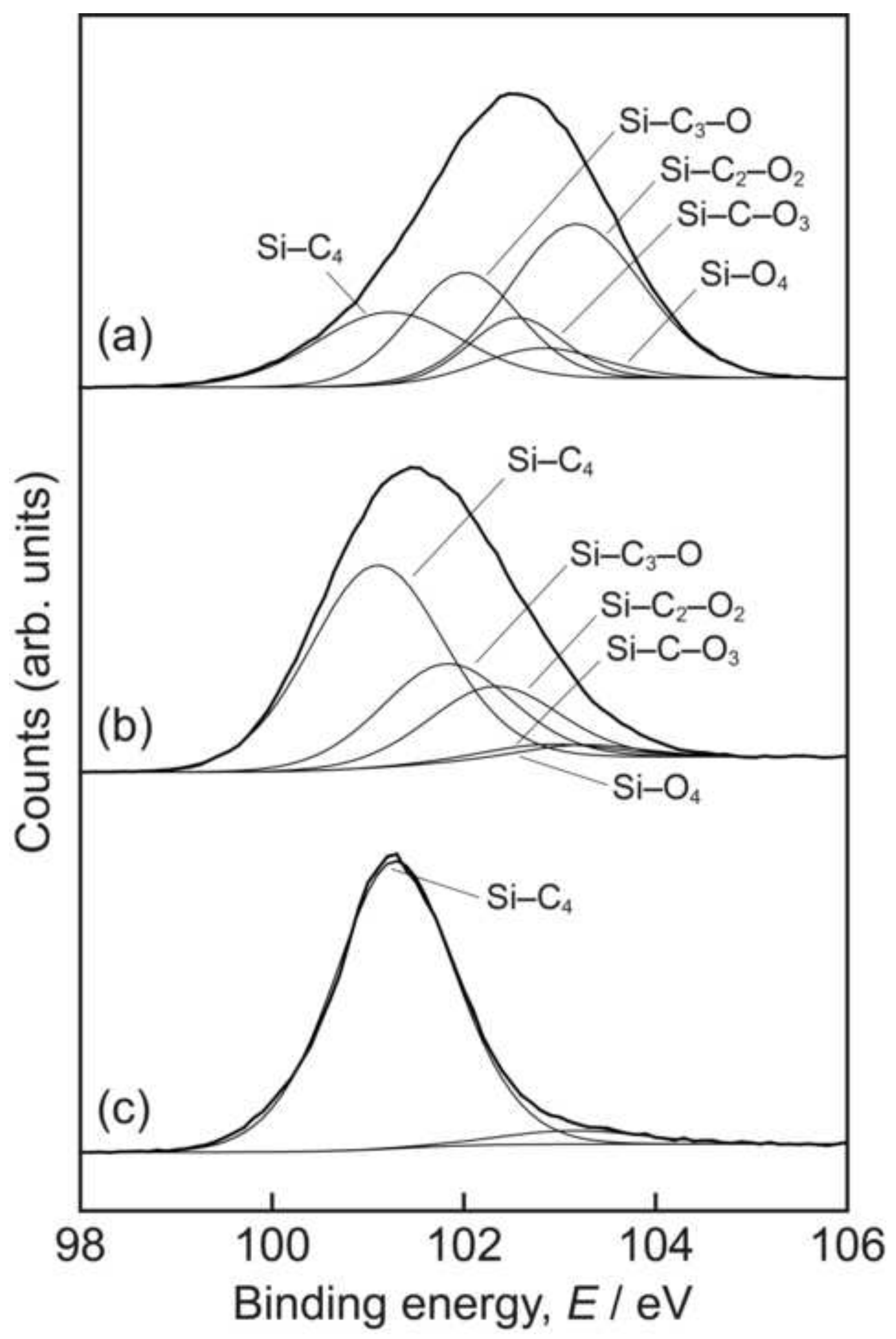




\section{Fig.06}

(a)

(b)

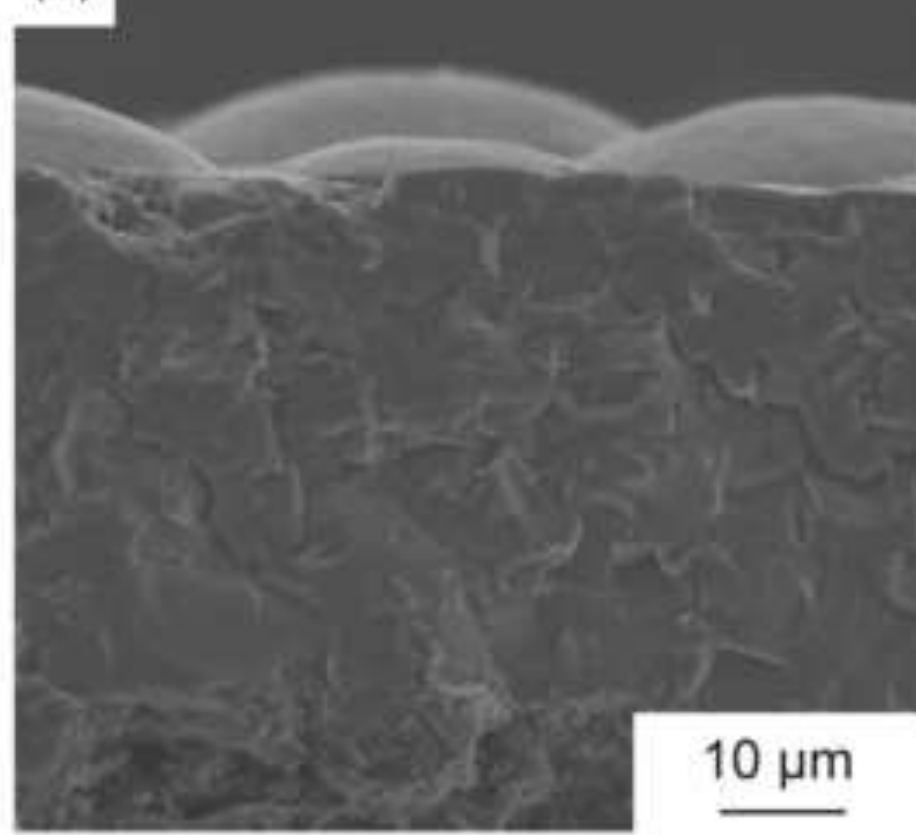

(c)

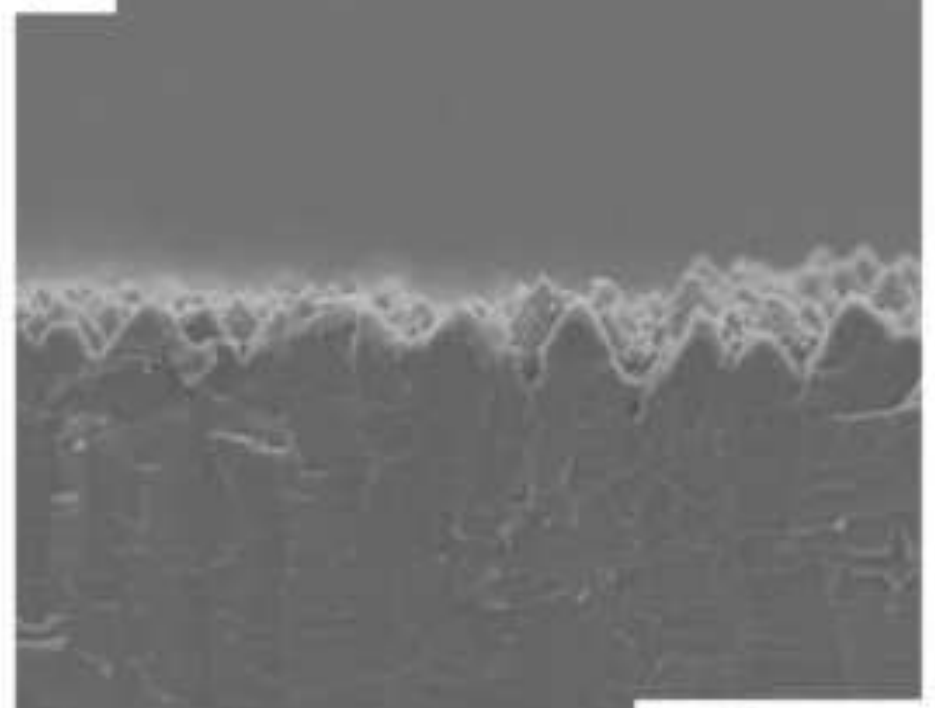

$10 \mu \mathrm{m}$

(d)

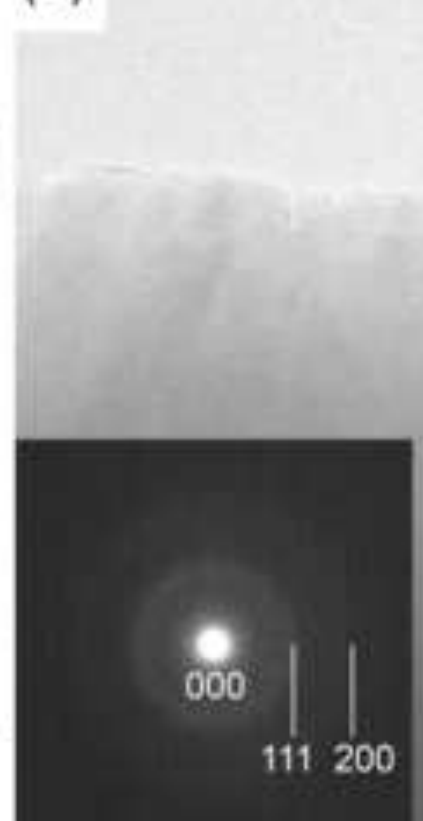

$500 \mathrm{~nm}$

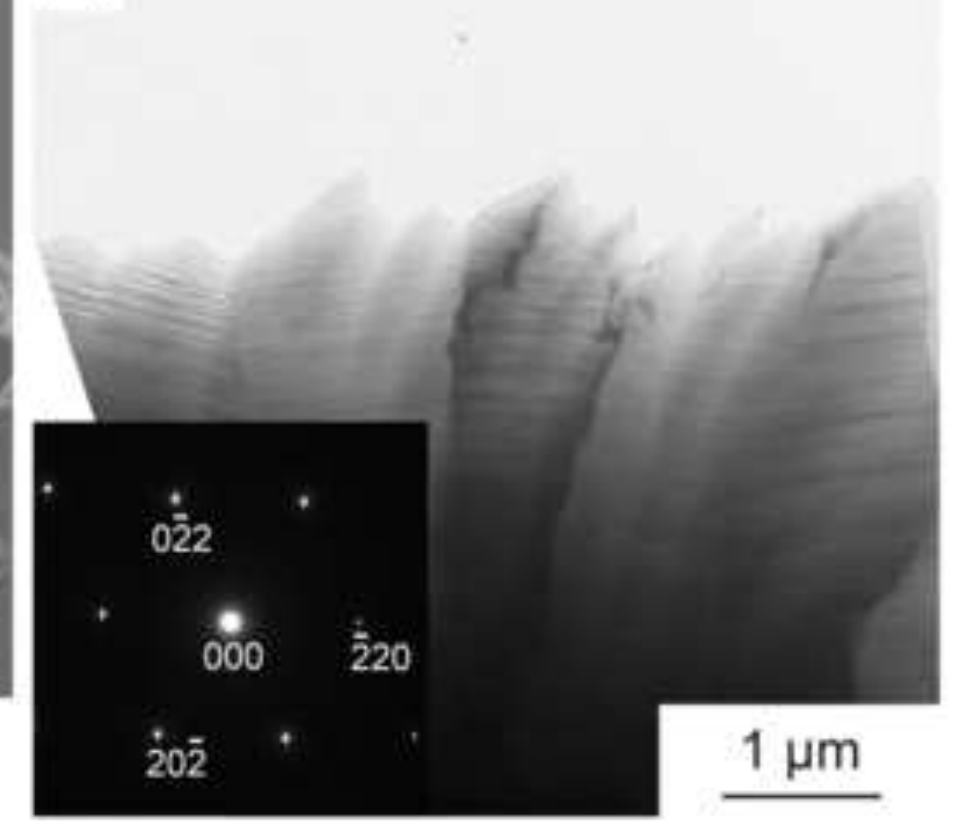




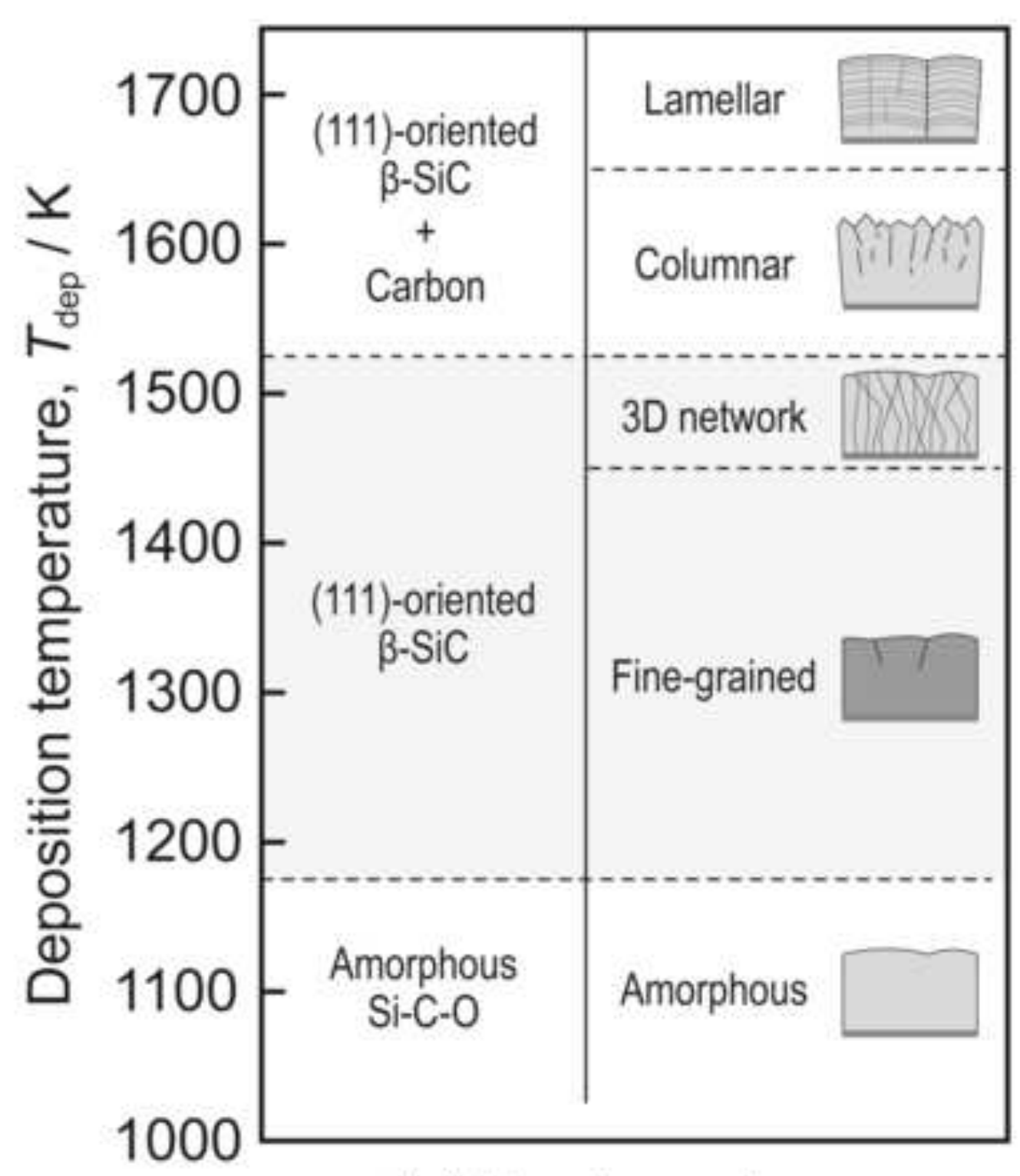

(a) $\mathrm{H}_{2}$ atmosphere

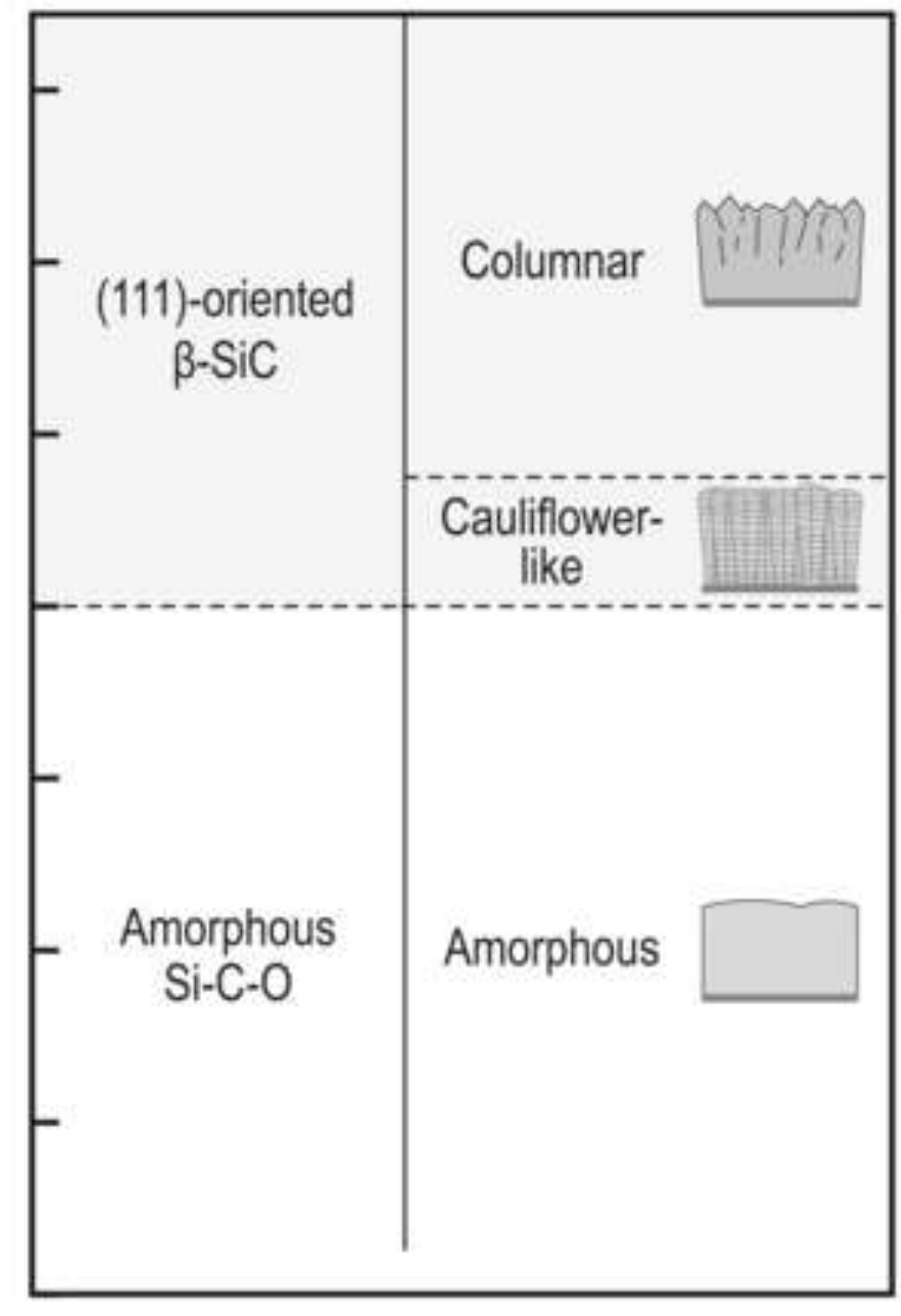

(b) Ar atmosphere 
Deposition temperature, $T_{\text {dep }} / \mathrm{K}$

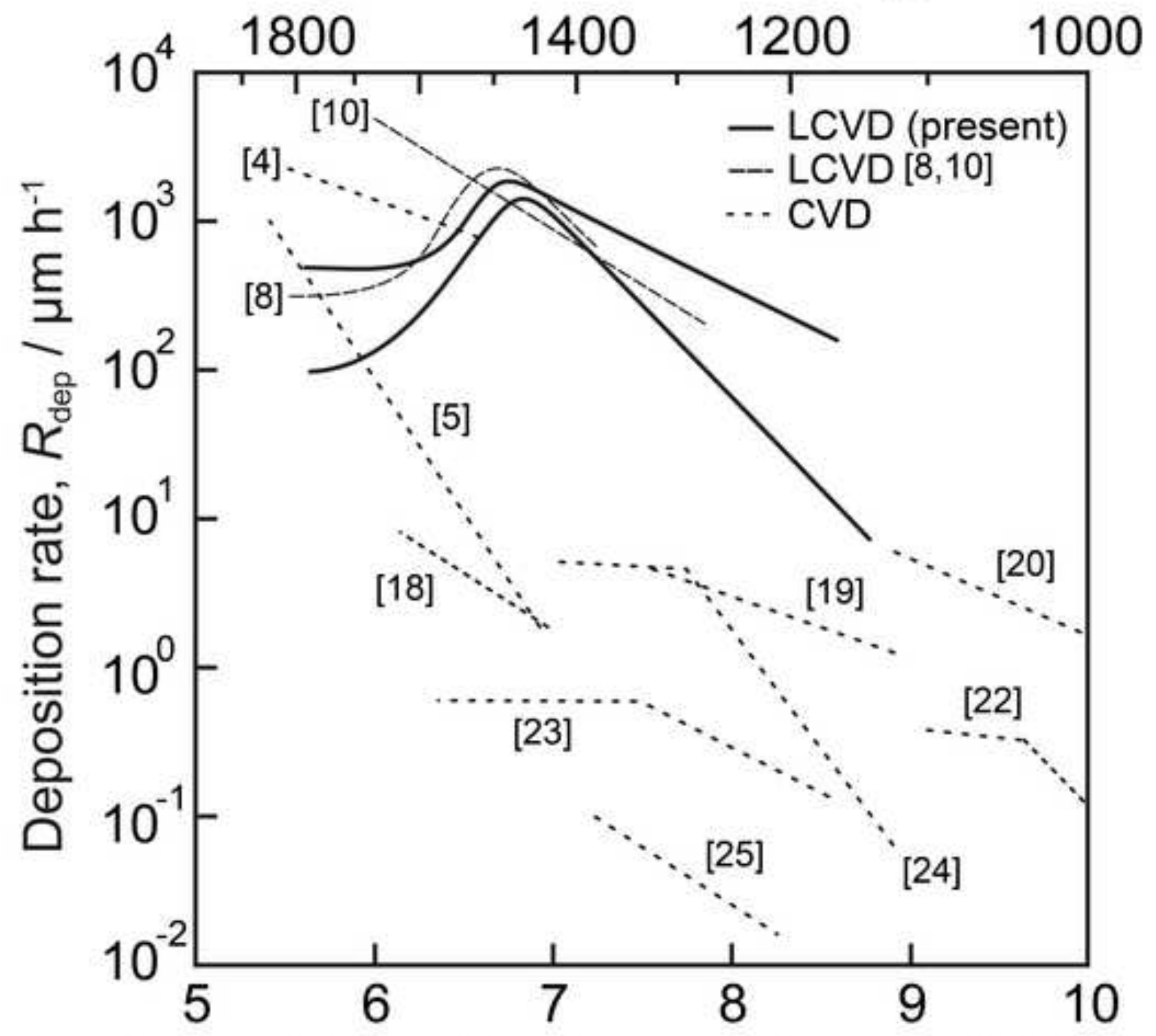

Reciprocal deposition temperature, $T_{\text {dep }}^{-1} / 10^{-4} \mathrm{~K}^{-1}$ 
Table 1 Preparations of SiC film by CVD in literature and in the present study.

\begin{tabular}{llllr}
\hline CVD type $^{\dagger}$ & Precursor $^{\dagger}$ & Reactant & Max. $R_{\text {dep }}\left(\mu \mathrm{m} \mathrm{h}^{-1}\right)$ & Ref. \\
\hline Halide CVD & & & & \\
LP, CW & $\mathrm{SiCl}_{4}$ & $\mathrm{H}_{2}+\mathrm{C}_{3} \mathrm{H}_{8}$ & 1400 & {$[4]$} \\
AP, CW & $\mathrm{SiCl}_{4}$ & $\mathrm{H}_{2}+\mathrm{C}_{3} \mathrm{H}_{8}$ & 1400 & {$[4]$} \\
LP, CW & $\mathrm{SiCl}_{4}$ & $\mathrm{H}_{2}+\mathrm{CH}_{4}$ & 1125 & {$[5]$} \\
PE, CW & $\mathrm{SiCl}_{4}$ & $\mathrm{H}_{2}+\mathrm{CH}_{4}$ & 8 & {$[18]$}
\end{tabular}

MOCVD

$\begin{array}{lllll}\text { LP, HW } & \text { HMDS } & \mathrm{H}_{2} & 3 & {[19]} \\ \text { LP, HW } & \text { TMS } & \mathrm{H}_{2} & 0.08 & {[25]} \\ \text { LP, HW } & \text { DSB } & - & 4 & {[24]} \\ \text { LP, CW } & \text { MMS } & \mathrm{H}_{2} & 0.5 & {[22]} \\ \text { AP, CW } & \text { HMDS } & \mathrm{H}_{2} & 4.5 & {[20]} \\ \text { AP, CW } & \text { HMDS } & \mathrm{H}_{2} & 0.6 & {[23]}\end{array}$

\section{Laser CVD}

\begin{tabular}{llllc} 
LP, CW & TEOS & $\mathrm{C}_{2} \mathrm{H}_{2}$ & 370 & {$[15]$} \\
LP, CW & HMDS & - & 2200 & {$[8]$} \\
LP, CW & HMDS & - & 3600 & {$[10]$} \\
LP, CW & HMDS & - & 2000 & Present \\
LP, CW & HMDS & $\mathrm{H}_{2}$ & 1400 & study \\
\hline
\end{tabular}

$\dagger$ LP: low-pressure CVD; AP: atmospheric-pressure CVD; CW: cold-wall type chamber; HW: hot-wall type chamber

† TMS (tetramethylsilane: $\left.\mathrm{Si}\left(\mathrm{CH}_{3}\right)_{4}\right)$; TMS (tetramethylsilane: $\left.\mathrm{Si}\left(\mathrm{CH}_{3}\right)_{4}\right)$; MMS (monomethylsilane: $\mathrm{CH}_{3} \mathrm{SiH}_{3}$ ); DSB (1,3-disilacyclobutane: $\mathrm{SiH}_{3} \mathrm{CH}_{2}-\mathrm{SiH}_{2} \mathrm{CH}_{3}$ ); HMDS (hexamethlydisilane: $\mathrm{Si}\left(\mathrm{CH}_{3}\right)_{3}-\mathrm{Si}\left(\mathrm{CH}_{3}\right)_{3}$ ); TEOS (tetraethyl orthosilicate: $\mathrm{Si}\left(\mathrm{C}_{2} \mathrm{H}_{5} \mathrm{O}\right)_{4}$ ) 